ORIGINAL ARTICLE

\title{
Investigating ethnic differences in sexual health: focus groups with young people
}

\author{
P Connell, C McKevitt, N Low
}

Sex Transm Infect 2004;80:300-305. doi: 10.1136/sti.2003.005181

See end of article for authors' affiliations

......................

Correspondence to: Dr N Low, Department of Social Medicine, University of Bristol, Bristol BS8 2PR, UK; nicola.low@bristol. ac.uk

Accepted for publication 19 November 2003

\begin{abstract}
Objectives: To compare normative beliefs about sexual health in young men and women from black Caribbean, black African, and white ethnic groups in order to better understand ethnic inequalities in sexual health.

Methods: Focus group discussions with young people living in an area with known high prevalence of gonorrhoea and chlamydia. Groups were stratified by sex and self defined ethnicity.

Results: 22 male and 20 female 16-25 year olds of black Caribbean, black African, and white ethnicity took part in eight discussions. Participants from black ethnic groups were more aware of gonorrhoea than white participants but all ethnic groups regarded these as being less important than unplanned pregnancy or HIV/AIDS. Most participants believed that they would have obvious symptoms if they had a sexually transmitted infection and could determine the cleanliness of sexual partners by visual or behavioural cues. Black Caribbean women were alone in acknowledging the likelihood of their partners having concurrent sexual relationships. Some black Caribbean women described negative attitudes of staff in genitourinary medicine clinics who were from the same ethnic background.

Conclusion: In this focus group study we identified ethnic differences in terminology, awareness of sexually transmitted infections, non-exclusive sexual relationships, and experience of sexual health services but gender had a greater influence on normative beliefs. The similarities in norms for all ethnic groups might reflect common social and cultural exposures. The low priority given to sexually transmitted infections by young people from all ethnic groups needs to be addressed if they are to be tackled successfully.
\end{abstract}

$\mathrm{T}$ here are marked ethnic disparities in reported rates of sexually transmitted infections. Gonorrhoea and chlamydia have been found to be 10 or more times higher in people from black Caribbean than white ethnic groups in England. ${ }^{12}$ New diagnoses of HIV infection also increased by $13 \%$ in black Caribbeans and by $23 \%$ in black Africans between 2001 and 2002 compared with a 5\% decrease in white people. ${ }^{3}$ These differences persist after statistically controlling for age at sexual debut, numbers of sexual partners, ${ }^{4}$ and material deprivation. ${ }^{1}$

Patterns of sexual mixing, partner choice, ${ }^{5-7}$ and cultural factors $^{8-10}$ are assumed to be important determinants of ethnic variations in sexual health but little qualitative research has investigated these. ${ }^{11} 12$ Despite recognition of black and minority ethnic groups as having special needs for prevention in the government's national strategy for sexual health and HIV $^{13}$ there is insufficient information about why such inequalities exist and how they should be addressed. Here we report findings from focus group discussions undertaken as part of a project investigating ethnic differences in sexual health. ${ }^{12}$ The objective of this study was to compare normative beliefs about sexual health and relationships among young people from black Caribbean, black African, and white ethnic groups. The study was approved by the research ethics committee of Guy's and St Thomas's Hospital Trust.

\section{METHODS}

\section{Setting}

The study took place from March to October 1999 among residents of the London boroughs of Lambeth, Southwark, and Lewisham whose sexual health is among the poorest in the United Kingdom. ${ }^{12}{ }^{14}$ Yearly rates of gonorrhoea are six to seven times the national average ${ }^{1}$ and $13 \%$ of all people seeking care for HIV infection live in the area. ${ }^{14}$

\section{Participants}

Participants were sought in youth centres and meeting places in the study area using contacts identified by key informants interviewed earlier in the project. ${ }^{12}$ We sampled purposively to obtain groups of four to six young people according to gender and three categories of self reported ethnic identity: black Caribbean, black African, and white. Participants gave written consent and received $£ 10$ each.

\section{Focus groups}

Groups took place in youth and leisure centres and lasted an average of 2 hours. A moderator (PC, an African Caribbean woman) stimulated discussion using a list of questions (see box), developed from a literature review, interviews with key informants, and observation of a young people's sexual health forum. ${ }^{12}$ The topic guide was tested with a male and female group. The moderator encouraged interaction and exploration of additional issues and ensured that all participants contributed. An assistant moderator took notes and summarised each discussion.

\footnotetext{
Analysis

Tapes were fully transcribed and a coding framework of themes developed. Text units were collated according to theme (QSR NUD*IST 4, Qualitative Solutions \& Research, Australia) using the constant comparison method of grounded theory in which the textual data are scrutinised for differences and similarities within themes. ${ }^{15}$ We compared themes across ethnic and gender groups and prioritised issues generating the most discussion, either as views expressed by a majority of participants or minority views that generated much discussion.
} 


\section{Topic guide for focus group discussions}

(1) Sex and relationships

(a) What are some of the things you look for in a relationship?

(b) Who would you define as a boy/girlfriend?

(c) Do you think people should stick to people from their own background in having a relationship? What is your experience in this regard?

(d) What are some of the difficulties you experience in relationships?

(e) Do you agree or disagree that sex should only be part of a steady committed relationship?

(f) What factors affect whether you decide to have sex with someone or not?

(g) Do you ever discuss with people you may be thinking of going out with anything about their sexual past?

(h) Do you ask them about infections which can be passed on by sex?

(i) Have there been times when you have made a decision not to have sex with someone?

(2) Knowledge of and attitudes to sexually transmitted infections

(a) Do you know the names of any infection that you can catch from having sex?

(i) What symptoms and

(ii) What problems do they cause?

(iii) How common do you think they are?

(b) How can you know if someone has an infection?

(c) Does the risk of catching an infection bother you?

(d) How would you feel if you found out that you had an infection like gonorrhoea (not HIV)?

(3) Views about sexual health services

(a) What would you/your friends do if you/they thought you/they had an infection?

(b) What would

(i) Encourage you to go for help?

(ii) Put you off going for help?

(4) Condom use

(a) What do you/friends think about using condoms?

(5) Social influences on sexual behaviour

(a) How did you learn about sex?

(b) Do you ever seek advice or discuss important issues about sex or relationships with other people?

(c) Do you ever feel pressures from others to act in particular ways?

(6) Ethnic identity and self perception

(a) What are the most important things in life to you right now?

(b) Is staying healthy important to you?

(c) Do you take any steps to ensure that you stay healthy?

(d) Finish this sentence, "Being a young black Caribbean/black African/white woman/man in Camberwell/Brixton/Forest Hill, etc, means..."

\section{RESULTS}

The characteristics of focus group participants are shown in table 1. Most were under 20 years, in full or part time education, and living with parents. We report the five major themes using illustrative quotations. All names are pseudonyms.

\section{Awareness of sexually transmitted infections}

Participants used both formal and informal terms, including "hicky" (rash) and "crabbies," and "jabbies" (generic terms). The listing of infections provoked laughter and denials of personal experience in all male groups. Women did not tease each other and repeatedly stated colleges as their sources of information.

Gonorrhoea was the first infection mentioned by black Caribbean men and women and the second (after HIV) by black African men and women. White men and women mentioned HIV first and white women expressed embarrassment at being able to name very few infections. Only black Caribbeans reported knowing someone having gonorrhoea, the admission by one participant leading to one or two other participants saying they also knew someone. Chlamydia was mentioned only by black women with participants from both black ethnic groups demonstrating their knowledge by stating facts they had learnt from leaflets or talks. The following extract shows a discussion among African women about their awareness and knowledge of chlamydia and HIV infection. They reached a consensus about their relative frequency and importance based on curability and the amount of public information about each infection.

- PC: What about chlamydia, do you think it's very common?

- Mia: Probably.

- Kerry: No. I mean, I've never heard of that you know, chlamydia ...

- Dionne: It's not a thing that you know, apparently it doesn't have any symptoms. [...]

- Mia: It's not as common as HIV.

- Kerry: Yeah or, you know something that has been publicised.

- Shanice: But don't forget that these are treatable ain't it.. and they're not. [...] You can get rid of them but you can't get rid of HIV, so there's more people catch HIV.

- PC: So you think they're not as common as HIV.

- Mia: Emhmm.

- Kerry: I do, I think they're more common.

- Mia: Not chlamydia.

- Kerry: Not that one, but maybe the other ones.

- Dionne: No one cares about the other ones.

- Mia: Because you see what, if you was to say I've got this, this this chlamydia and you try and find the clinic it would be hard for you but if you say you've got HIV or gonorrhoea or or something then people will, someone will say to you "oh go to your doctors" or something like that.

Focus Group \#5, black African women

Shanice also observed that a relation exists between prevalence and the duration of infection, stating that more people could be exposed to an infection that persists in the absence of a cure. In this discussion the asymptomatic nature of chlamydia was also noted but in general participants in all groups believed that they would have noticeable symptoms such as a discharge or itchiness if they had a sexually transmitted infection. 
Table 1 Profile of focus groups and participants

\begin{tabular}{|c|c|c|c|c|c|c|}
\hline & \multicolumn{3}{|l|}{ Female } & \multicolumn{3}{|l|}{ Male } \\
\hline & Black Caribbean & Black African & White & Black Caribbean & Black African & White \\
\hline Total participants & 12 & 4 & 4 & 5 & 11 & 6 \\
\hline Focus groups & 2 & 1 & 1 & 1 & 2 & 1 \\
\hline Age range (years) & $16-24$ & $16-18$ & $15-18$ & $16-18$ & $15-23$ & $16-18$ \\
\hline \multicolumn{7}{|l|}{ Occupation } \\
\hline Full/part time education & 8 & 4 & 3 & 3 & 9 & 3 \\
\hline Other & 4 & 0 & 1 & 2 & 2 & 3 \\
\hline \multicolumn{7}{|l|}{ Living arrangements } \\
\hline Parents' home & 5 & 4 & 4 & 5 & 10 & 6 \\
\hline Other & 7 & 0 & 0 & 0 & 1 & 0 \\
\hline
\end{tabular}

\section{Sexual health priorities}

We identified the same hierarchy of concerns in all ethnic groups.

\section{Unplanned pregnancy}

Women unanimously identified unplanned pregnancy as their main fear:

- Reanna: I think it still boils down to the fact that pregnancy is what scares most young people.

- PC: So you're more worried about becoming pregnant than about catching gonorrhoea or ...

- [Several voices: 'Yeah' cross talking] [...]

- PC: OK but when ... you're thinking about having sex with someone does that [sexually transmitted infections] come into your mind?

- Shamika: No not really it's more pregnancy I suppose.

Focus Group \#1, black Caribbean women

Men's concerns about pregnancy were expressed in terms of the need for the girl to take responsibility and fears of fatherhood.

\section{HIV and AIDS}

In the following excerpt both AIDS and infertility were discussed as incurable consequences of sexually transmitted infections but AIDS was considered more serious because it is fatal.

- PC: What about the others like gonorrhoea?

- Kerry: Most of them can be cured, so you don't really...

- Dionne: But AIDS, that's what I think about.

- PC: Finish what you were saying.

- Kerry: They can be cured, it's not like you don't care if you get any. You care yeah but you know there's a cure for it. But AIDS there's no cure for it it really does...

- Mia: Some of them you can't, when you have it, you can't have babies any more.

- Kerry: Yeah I know that, but you can adopt.

- Dionne: But if you're dead then you can't do that.

Focus Group \# 5, black African women

In the black Caribbean men's group one participant noted that HIV would mark one as a "batty man" [homosexual]. This was endorsed by others accompanied by a constant stream of participants playfully characterising each other as gay men and defending themselves against the accusation.

\section{Other sexually transmitted infections}

As shown in the two excerpts above, other sexually transmitted infections were viewed as being less serious than HIV because they were curable and not fatal. When these were described as minor infections other group members did not challenge the perception. Participants across groups, however, agreed that they would feel angry, "dirty," or embarrassed if they had a bacterial infection.

\section{Reducing the risk of sexually transmitted infections}

Strategies to avoid sexually transmitted infections were discussed in the context of sexual relationships, rather than using protective measures like condoms.

\section{Avoiding risky people}

All groups named prostitutes, gay men, lesbians, drug users and promiscuous people as "risky types," without being challenged by other members. Women in all groups reported avoiding men with a reputation for having many sexual partners, "players," in the terminology of black African women, but acknowledged their attraction because they were seen as exciting. Men across ethnic groups reported that they were wary of women who gave in easily to sexual requests, flirted, or who initiated sex early on in the relationship. All groups of participants engaged in discussions that "blamed" the other gender for spreading sexually transmitted infections.

\section{Trust and risk}

Individuals from all ethnic groups linked condom use to building trust, with less use as trust was built up. Only black Caribbean women openly acknowledged the possibility of non-exclusive sexual relationships. In both groups women mentioned their trust in the exclusivity of the relationship as a reason for not using condoms. As the following example shows, however, they were also aware of the risk of acquiring sexually transmitted infections:

- Pam: ... as far as I'm concerned, it's bad for a man to be unfaithful yeah it is but at the end of the day, if he's got his personal woman indoors... I mean it's a bit disrespectful to sleep with someone else yeah, but that's just total lack of respect if you're gonna just go and sleep with them just so.

- Anna: Yeah, not use a condom.

- Pam: Not use nothing and know that you're going back to someone who trusts you and is not going to use something with you. And you don't know what you've got from them, nah it's the end...

Focus group \#3, black Caribbean women

A minority of men across ethnic groups emphasised that building trust was only necessary if the intention was to see the person again, which was not always the case. This view did not elicit further comment from other participants. 


\begin{abstract}
Assessing risk
Men but not women, placed great reliance on a partner being "clean," a term used by all ethnic groups. Men discussed using visual cues such as type of clothes and reputation, usually gleaned from male friends. Discussions of girls' reputation led to descriptions in all male groups of girls whom they considered to be disreputable. Individual accounts were confirmed and stories added about other girls considered to be of similar repute. Such sharing of stories about particular individuals was not a feature of women's groups. There were ethnic differences in the terminology for women who "slept around." White men used "slag" or "slapper," black Caribbean men used "jezzy" or "sket," and black African males used both. Black Caribbean and African men referred to "wifey" or "girlfriend material" for women with whom they would have a more serious relationship and linked this to the lesser likelihood of them having an infection.
\end{abstract}

\section{Sexual mixing according to ethnic group}

Participants from all ethnic groups concurred that it was up to the individual to choose a sexual partner from any social or ethnic group. Most individual accounts, however, demonstrated a personal preference for partners from their own ethnic background and were linked to parental views.

- Mark: Some people their parents won't have it. Like I know if I bring a white girl...

- PC: Won't have what?

- Mark: Mixed, if I bring a white girl home my mum wouldn't have a part of it

- Andre: Same thing with my mum like she wouldn't have it $[\ldots]$

- Ricky: What about like if like she's like she's really beautiful?

- Mark: If she is like I can't knock it. If she is and I like her, "wraughted" [phwoar], then I'm going out with her but I can't take her home. Because my mum would not like her in the yard. And I want to stay home and eat some good food. [laughter]

Focus Group \# 4, black Caribbean men

When a participant in each of the black Caribbean and white men's groups made the distinction between short term relationships with partners from other ethnic backgrounds and "settling down" with someone from their own ethnic group others agreed and contributed their own personal examples. These discussions also referred to wider social pressures where mixed relationships were eschewed, and children of mixed ethnicity experience problems because of divergent ethnic allegiances.

\section{Sexual health services}

In all groups most participants said that they would go to their general practitioner first if they suspected that they had an infection. Only black Caribbean women said that they had visited genitourinary medicine clinics. The consultations were for check-ups rather than symptoms. Three separate visits were reported, two of which were personal accounts and one a story about two friends. In the ensuing discussions other group members supported the view that more sensitivity from clinic staff was needed. Two accounts involved black staff members treating young black women differently from clients from other ethnic groups.

- Cerise: ... she was like really impatient with them and it was the case that she used to, she looked them up and down as if to say they were cheap or they were trash...
- Anna: Was she older?..

- Cerise: She was an older... woman, she was a bit like a mother herself.

- Pam: I find that older nurses you know are a bit stiff. Was she a black woman?

- Cerise: She was a black woman.

\section{[Talking together]}

- Pam: I've had a experience with black woman as well... You know the things they use the, [speculum] right... I said to the lady "ouch", you know, get a smaller one kind of thing. "What do you mean get a smaller one?" ...I can't remember exact her exact words but like you know... I never went back.

- PC: She was very rude to you? [Participants talking together]

- Anna: But that's feisty.

- Pam: Yeah. And I bet you if it was a white girl came in there, she wouldn't do that, she wouldn't say that.

- PC: Why do you think she was harder on you? Because you were black?

- Pam: It's her own. [same ethnic background] [...]

- PC: But why do you think she was hard on you as a black woman?

- Pam: Personally I can't see any reason why she should be, but she was, and I can't really put my finger on why just because I was black ... and that maybe she thought that you should know ... as a black young ... whatever. I don't know her excuse.

Focus Group \# 3, black Caribbean women

\section{DISCUSSION}

This study compared normative beliefs about sexual health in young people from different ethnic groups. Young black people were more aware of gonorrhoea and chlamydia than their white peers but these infections were not a serious concern for any ethnic group. Only black Caribbean women acknowledged the existence of non-exclusive sexual relationships and their consequent susceptibility to sexually transmitted infections. Black Caribbean women also reported negative experiences when visiting genitourinary clinics. Gender differences were more marked than ethnic differences.

\section{Methodological issues}

The strengths of this study are that it was community based and involved people from ethnic groups at high risk of sexually transmitted infections. We used focus group discussions in order to compare normative beliefs of different ethnic groups, some of which might be targeted in interventions to reduce the risk of sexually transmitted infections. Focus groups have been recommended for both sexual health ${ }^{16}$ and cross cultural research. ${ }^{17}$

This study involved 42 young people from black Caribbean and African backgrounds, compared with $13^{11}$ and $12^{18}$ from similar age and ethnic groups in other published reports. The main weakness is, however, its size, which was limited by the sensitive topic and the hard to reach target groups. Sampling was purposive and we were unable to assess differences between those agreeing and declining to participate. While the number of groups might be considered too small to reach saturation of emergent themes we think that our findings are robust since they are consistent with studies investigating similar constituencies but using different qualitative methods. ${ }^{11} 18$

The personal characteristics of the moderator could also have influenced responses. ${ }^{19}$ As an African Caribbean woman she was ethnicity matched with only a third and gender 
matched with only half of the groups. White women have described difficulties interviewing black women ${ }^{19}$ but the reverse has not been reported. With reference to gender and sexuality unmatched researchers have been reported to elicit more and different information because they are not seen to be threatening. ${ }^{20}$

\section{Ethnicity}

Many studies have described associations between ethnicity and health but less attention has been paid to the underlying mechanisms. ${ }^{81}$ We aimed to situate the problem of sexually transmitted infections within its social and cultural context. Historical and economic factors and their effects on contemporary social forces have also been used as a context for explaining ethnic differences in syphilis rates in the southern United States. ${ }^{22}$ We found few striking differences in the group norms of young people from the three ethnic groups. This may reflect the "ethnicity" of the participants who self identified as black Caribbean, African, or white but were mostly born and educated in London. Age and sex have previously been reported as having a stronger influence than ethnicity on sexual lifestyles. ${ }^{11}$ The blurring of "cultural" differences among second and third generation ethnic minorities has been documented in relation to both teenage parenthood $^{23}$ and sexual lifestyle. ${ }^{8}$

\section{Sex differences}

There were clear differences across ethnic groups between women's and men's attitudes towards sexual health priorities, relationships, and risk reduction strategies. Men used humour to defuse what they perceived as embarrassing discussions whereas women were more likely to use factual information to discuss sensitive issues. Holland has argued that ethnic group similarities and gender differences arise because the definition of heterosexual sex is male oriented and the language and experience of women from all ethnic groups is shaped by their subordinate position within sexual relationships. ${ }^{18}$ Our findings support this hypothesis and suggest that intervention strategies need to take into account the gendered way in which sexuality and sexual behaviours are constructed.

\section{Public health implications}

Bacterial sexually transmitted infections ranked well behind pregnancy and HIV avoidance as sexual health concerns. ${ }^{18}{ }^{24}$ We have now shown that this hierarchy of risk persists across ethnic groups with very different prevalence of infections. ${ }^{12}$ Prominent public information about teenage pregnancy and

\section{Key messages}

- Young black Caribbean people are at disproportionately high risk of sexually transmitted infections compared with other ethnic groups.

- There is insufficient information about why such inequalities exist and how they should be addressed.

- We found ethnic differences in terminology, awareness of sexually transmitted infections, the possibility of nonexclusive sexual relationships and experience of sexual health services but gender had a greater influence on normative beliefs.

- Bacterial sexually transmitted infections were not considered as a serious concern by young people from any ethnic group and this belief must be challenged if interventions are to be effective.
HIV/AIDS reinforced the impression among participants that these conditions were more common than chlamydia. In fact, in 2001 over 70000 new chlamydia infections were reported ${ }^{25}$ compared with around 38000 conceptions in under 18 year olds $^{26}$ and 2000 new HIV infections. ${ }^{3}$ Since bacterial infections are common and cause substantial morbidity specific campaigns are warranted, particularly in high prevalence areas.

Sexual health services are perceived as being unfriendly to black people in general ${ }^{11}{ }^{12}$ but some black Caribbean women in this study reported negative attitudes from staff members from the same ethnic background. There is a long history of negative racial ${ }^{27}$ and sexual ${ }^{28}$ stereotyping of black people in the United Kingdom and, while such treatment may reflect concerns about young black people's health, these health workers may also perceive young black women's presence in genitourinary medicine clinics as an embarrassment. Our study shows that racial awareness training is important for healthcare practitioners irrespective of ethnic group.

We have used information from this study to develop an intervention to increase knowledge and diagnosis of asymptomatic gonorrhoea and chlamydia, challenging the widespread beliefs that people with sexually transmitted infections always have symptoms or can be identified through visual and behavioural cues. ${ }^{29}$ The intervention was delivered separately to women and men and was geographically targeted to areas with large populations of black Caribbean residents to include those at highest risk of infection without stigmatising individual ethnic groups.

\section{CONCLUSIONS}

In this focus group study we identified ethnic differences in terminology, awareness of sexually transmitted infections, non-exclusive sexual relationships, and experience of sexual health services but gender had a greater influence on normative beliefs about sexual health. Preventive interventions should target bacterial sexually transmitted infections and these need to take into account the gendered way in which sexuality and sexual behaviours are constructed.

\section{ACKNOWLEDGEMENTS}

This work was undertaken by the Department of Social Medicine, University of Bristol and Department of Public Health Sciences, King's College London, who received funding from the Department of Health. The views expressed in the publication are those of the authors and not necessarily those of the Department of Health.

We would like to thank all the participants in this research project for trusting us with their information.

\section{CONTRIBUTORS}

PC conducted the focus groups, did the analysis, wrote the first draft of the paper and contributed to the revised versions; CMcK helped design the study, and contributed to the analysis and revisions of the paper; NL had the idea for and helped design the study, contributed to the analysis, and revised the paper.

\section{Authors' affiliations}

P Connell, C McKevitt, Department of Public Health Sciences, Kings College London, 5th Floor, Capital House, 42 Weston Street, London SEl 3QD, UK

N Low, MRC Health Service Research Collaboration, Department of Social Medicine, University of Bristol, Canynge Hall, Whiteladies Road, Bristol BS8 2PR, UK

Dr Nicola Low is supported by a NHS Career Scientist Award.

\section{REFERENCES}

1 Low N, Daker-White G, Barlow D, et al. Gonorrhoea in inner London: results of a cross sectional study. BMJ 1997;314:1719-23.

2 Shahmanesh M, Gayed S, Ashcroft M, et al. Geomapping of chlamydia and gonorrhoea in Birmingham. Sex Transm Infect 2000;76:268-72. 
3 HPA, SCIEH. AIDS/HIV quarterly surveillance tables. UK Data to End June 2003. 58: 03/1, 1. 2003. London: Health Protection Agency and the Scottish Centre for Infection \& Environmental Health. 23 October 2003.

4 Ellen JM, Aral SO, Madger LS. Do differences in sexual behaviors account for the racial/ethnic differences in adolescents' self-reported history of a sexually transmitted disease? Sex Transm Dis 1998;25:125-9.

5 Barlow D, Daker-White G, Band B. Assortative sexual mixing in a heterosexual clinic population-a limiting factor in HIV spread? AIDS 1997;11:1041-6.

6 Laumann EO, Youm Y. Racial/ethnic group differences in the prevalence of sexually transmitted diseases in the United States: a network explanation. Sex Transm Dis 1999;26:250-61

7 Aral SO, Hughes JP, Whittington W, et al. Sexual mixing patterns in the spread of gonococcal and chlamydial infections. Am J Public Health 1999:89:825-33.

8 Fenton KA. Strategies for improving sexual health in ethnic minorities. Curr Opin Infect Dis 2001;14:63-9.

9 Quimby E. Anthropological witnessing for African Americans: power, responsibility, and choice in the age of AIDS. In: Herdt G, Lindenbaum S, eds. The time of AIDS. London: Sage, 1992.

10 Lambert H. Methods and meanings in anthropological, epidemiological and clinical encounters: the case of sexually transmitted disease and human immunodeficiency virus control and prevention in India. Trop Med Int Health 1998;3:1002-10.

11 Elam G, Fenton K, Johnson AM, et al. Exploring ethnicity and sexual health. London: SCPR, 1999.

12 Connell P, McKevitt C, Low N. Sexually transmitted infections among Black young people in South East London: results of a rapid ethnographic assessment. Culture, Health and Sexuality 2001;3:311-27.

13 Department of Health. National strategy for sexual health and HIV. London: DoH, 2001

14 Lambeth, Southwark and Lewisham Health Authority. Annual report of the Director of Public Health 2001/2002. London: Lambeth, Southwark and Lewisham Health Authority, 2002

15 Glaser BG, Strauss AL. The discovery of grounded theory. Chicago: Aldine, 1967.

16 Power $\mathbf{R}$. The application of qualitative research methods to the study of sexually transmitted infections. Sex Transm Infect 2002;78:87-9.
17 Kitzinger J. Focus groups with users and providers of health care. In: Pope C, Mays N, eds. Qualitative research in health care. London: BMJ Books, 1999:20-9.

18 Holland J. Sexuality and ethnicity: variations in young women's sexual knowledge and practice. London: Tufnell Press, 1993.

19 Edwards R. Connecting method and epistemology: a white woman interviewing black women. Women's Studies International Forum 2001;13:477-90.

20 Warren CAB, Rasmussen PK. Sex and gender in field research. Urban Life 1977;6:349-69.

21 Bhopal R. Is research into ethnicity and health racist, unsound, or important science? BMJ 1997;314:1751-6.

22 Thomas JC, Thomas KK. Things ain't what they ought to be: social forces underlying racial disparities in rates of sexually transmitted diseases in a rural North Carolina county. Soc Sci Med 1999:49:1075-84.

23 Phoenix A. Narrow definitions of culture: the case of early motherhood. In: Westwood S, Bhachu P, eds. Enterprising women. Ethnicity, economy and gender relations. London: Routledge, 1988:153-76.

24 Kent V, Davis $M$. Social interaction routines in heterosexual encounters of young people. In: Glanz A, McVey D, Glass R, eds. Talking about it: young people, sexual behaviour and HIV. London: Health Education Authority, 1993:4-21

25 PHLS, DHSS \& PS, Scottish ISD(D)5 Collaborative Group. Sexually Transmitted Infections in the UK. New episodes seen at genitourinary medicine clinics, 1991-2001. Trends in sexually transmitted infections with special reference to surveillance developments. London: PHLS, 2002:1-46.

26 Teenage Pregnancy Unit. Conception statistics for 1998-2001. England. (www.info.doh.gov.uk/doh/users.nsf/fs 1 ? readForm) Accessed 30-10- 2003.

27 James W. Migration, racism and identity formation: the Caribbean experience in Britain. In: James W, Harris C, eds. Inside Babylon: the Caribbean diaspora in Britain. London: Verso, 1993.

28 Mama A. Beyond the masks: race, gender and subjectivity. London: Routledge, 1995

29 Low N, Connell P, McKevitt C, et al. "You can't tell by looking." Community-based intervention to detect asymptomatic sexually transmitted infections. Int J STD AIDS 2003;14:830-4.

\section{$\mathrm{ECHO}$}

\section{HAART restores balance of mucosal immunity in advanced AIDS}

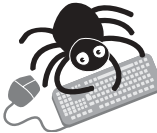

Please visit the Sexually Transmitted Infections website [www. stijournal.com] for a link to the full text of this article.
$P$ atients receiving highly active antiretroviral treatment (HAART) for advanced AIDS should be able to benefit from future vaccines delivered mucosally to control the disease, as HAART restores homoeostasis of intestinal B cells, a long term study has confirmed.

Intestinal B cell activity during simple treatment for AIDS during 1991-6 was compared with activity during treatment with HAART two years subsequently and activity in healthy controls. HAART significantly reduced number of cells producing IgA per $500 \mu \mathrm{m}$ length of duodenum (median number $112 \mathrm{v} 181$ ) and normalised the proportion producing IgGlwhen compared with no treatment or other treatments. It also increased CD4 cell number and lowered viral load. Immunocytes producing IgA, IGM, or total IgG were found in similar median proportions in the HIV positive patients and controls.

Duodenal biopsy and peripheral blood specimens were taken consecutively from 31 HIV-1 positive patients, mostly with advanced AIDS and all with various HIV associated infections, and from 11 age matched HIV negative healthy volunteers during 1991-8. The biopsy specimens were used to determine the number and type of mucosal antibody producing $\mathrm{B}$ cells by in situ two colour immunofluorescence staining, and the blood samples to determine amounts of retroviral RNA.

The ability of HAART to stabilise mucosal immunity, as it does systemic immunity, has been doubtful, owing to conflicting study results. This study suggests that HAART restores normal balance to mucosal immunity, making potential immunisation by the mucosal route a realistic prospect for AIDS patients.

A Gut 2004;53:487-493. 